\title{
Drought Mapping Using Two Shortwave Infrared Water Indices with MODIS Data under Vegetated Season
}

\author{
S. H. Zhao ${ }^{1}$, Q. Wang ${ }^{1}$, F. Zhang, ${ }^{1, *}$, Y. J. Yao ${ }^{2}$, Q. M. Qin ${ }^{3}$, L. You ${ }^{4}$ J. P. Li ${ }^{5}$, Z. J. Li ${ }^{6}$, Y. T. Wu ${ }^{1}$, S. H. Liu ${ }^{1}$, and Y. Li $^{1}$ \\ ${ }^{I}$ Satellite Environment Center, Ministry of Environmental Protection, State Environmental Protection Key Laboratory of Satellite Remote Sensing, \\ Beijing 100094, China \\ ${ }^{2}$ College of Global Change and Earth System Science, Beijing Normal University, Beijing 100875, China \\ ${ }^{3}$ Institute of Remote Sensing and Geographic Information System, Peking University, Beijing 100871, China \\ ${ }^{4}$ Ningbo Planning and Geography Information Center, Ningbo 315042, China \\ ${ }^{5}$ Ningxia Provincial Institute of Meteorology, Yinchuan 750002, China \\ ${ }^{6}$ Institute of Electronics, Chinese Academy of Sciences, Beijing 100190, China
}

Received 31 December 2011; revised 25 September 2012; accepted 16 January 2013; published online 27 June 2013

\begin{abstract}
Drought monitoring is a critical element for agricultural production, food security, water resource management, sustainable development, and a healthy environment. In this study, shortwave infrared (SWIR) bands with strong water absorption features were used to establish a physically significant water stress index. Two types of indices including SWIR water stress index (SIWSI) and SWIR perpendicular water stress index (SPSI) were constructed using near-infrared (NIR) and SWIR bands. A representative (semi) arid region in the Ningxia Plain of northwestern China, where droughts are frequent, was used to assess the state of dryness using the SIWSI and SPSI indices derived from NIR channel 2 (858 nm) and SWIR channel 6 (1640 nm) or channel 7 $(2130 \mathrm{~nm})$ of moderate-resolution imaging spectroradiometer (MODIS) sensor in combination with ground measurements. Fitted regressions indicate significant correlations $(\mathrm{P}<0.01)$ among both indices with the in-situ measurements. Generally, larger indices indicate drier lands, and correlations in the $10-\mathrm{cm}$ range were better than those in the $20-\mathrm{cm}$ range. Although SIWSI6, 2 ( $\mathrm{r} 2=0.75$, $0.74)$ performs slightly better than SIWSI7, $2(\mathrm{r} 2=0.73,0.71)$, SPSI6, $2(\mathrm{r} 2=0.70,0.69)$ performs marginally weaker than SPSI7, 2 $(\mathrm{r} 2=0.76,0.74)$. Ultimately, all four indices reflected dry state under clear sky conditions in the Ningxia Plain.
\end{abstract}

Keywords: SWIR, NIR, SIWSI, SPSI, Ningxia Plain

\section{Introduction}

Drought is a global phenomenon and a critical factor that limits plant survival and development. Drought is an extended period (months or years) of water shortage in a given region. Among the factors significantly relevant to drought are soil moisture and evapotranspiration. Knowledge about the timing, severity, and duration of drought is critical for drought-related planning and decision making (Tadesse et al., 2005). Severity of drought can be assessed as a function of moisture content, time duration, and the affected area. Although indices are commonly used to determine the state of drought, no index is suitable in all hydro-climatic conditions. Thus, different indices have different strengths in detecting different drought conditions.

Currently, functions integral to drought monitoring are drought planning, drought preparedness, and drought mitigation

\footnotetext{
* Corresponding author. Tel.: +86 10 58311595; fax: +86 1058311501.

E-mail address: zhang-fengs@163.com (F. Zhang).
}

ISSN: 1726-2135 print/1684-8799 online

(C) 2013 ISEIS All rights reserved. doi:10.3808/jei.201300237 at regional, national, and local levels. The dynamic nature of drought poses tremendous challenge in planning, predicting, monitoring, and providing relief to drought-stricken regions. Drought variability with unpredictable multi-impacts dictates the need for improvements in available tools to efficiently capture the spatial and temporal dimensions of a drought condition.

Several possible ways of monitoring drought include the use of ground measurements, hydrological data, climatological data as well as using remote sensing data. Traditional methods of drought assessment and monitoring rely on rainfall data, which are limited in space, often inconsistent, inaccurate, and difficult to obtain in real time. In contrast, however, satellitesensor data are consistent, globally available, and can be used to detect the onset, duration, and magnitude of a drought (Thiruvengadachari and Gopalkrishna, 1993).

Several studies have excellent contributions on acquisition of drought parameters using remote sensing data (Nemani et al., 1993; Ghulam et al., 2007a, b; Ghulam et al., 2008; Qin et al., 2008; Sandholt et al., 2002). Monitoring drought at high temporal and spatial resolutions in pinpoints areas with most severe droughts is important for rational reallocation of scarce water resources in order to mitigate collateral losses. In China, especially in northwestern China, drought is among the most se- 
vere natural disasters and it accounts for over half of the total agricultural loss in the country. Therefore, the development of practicable strategies to monitor drought in cultivated regions of China is critical and meaningful in mitigating losses and ensuring food security.

In monitoring drought via remote sensing, soil moisture or vegetation water content data is used in combination with related models/indices, optical reflectance, thermal-infrared (TIR), or microwave remote sensing data. In this study, microwave data are not introduced because of their complexity and long-temporal resolution. Currently, optical reflectance and TIR band methods focus mainly on vegetation or drought indices such vegetation condition index (VCI; Kogan, 1990, 1995), vegetation supply water index (VSWI; Carlson et al., 1990, 1994), temperature-vegetation index (TVX; Lambin and Ehrlich, 1995, 1996), temperature vegetation dryness index (TVDI; Sandholt et al., 2002), SWIR water stress index (SIWSI; Fensholt and Sandholt, 2003), and SWIR perpendicular water stress index (SPSI; Ghulam et al., 2007a).

VCI, VSWI, TVX, and TVDI use normalized difference vegetation index (NDVI) and occasionally in combination with land surface temperature (LST), which are in turn based on red, infrared, near-infrared (NIR) reflectance, and TIR emissivity. However, drought monitoring approaches based on NDVI have time lags following drought occurrence (Qin et al., 2008). Moreover, methods based on LST and NDVI (e.g., TVDI) usually need constructions of triangle or trapezoid spaces. Once such space is the LST-NDVI feature space, which requires a study area large enough to define dry and wet edges where errors could easily occur in the process analyses. SIWSI and SPSI use only NIR and shortwave infrared (SWIR) band reflectance in accessing soil moisture or vegetation water content, and therefore do not need thermal bands. A multitude of studies (Fensholt and Sandholt, 2003; Ghulam et al., 2007a, b) has shown that SWIR reflectance $(1300 \sim 2500 \mathrm{~nm})$ from satellite data is sensitive to variations in vegetation/soil water. NIR band $(858$ $\mathrm{nm}$ ) has been identified as a good choice for reference band suitable for normalization, owing to its relative insensitivity to variations in vegetation/soil water content compared to the longer wavelengths of NIR and SWIR bands. Hence, in this study, the SWIR bands (with strong water absorption features) are used to construct SIWSI and SPSI physically meaningful water stress indices.

MODIS data are widely used for detecting droughts because of their high temporal resolution and 36 bands, which also include three SWIR bands. MODIS data product MOD09A provides calibrated reflectance for seven spectral bands in the $400 \sim 2500 \mathrm{~nm}$ spectral interval at $500 \mathrm{~m}$ pixel resolution (http://modis.gsfc.nasa.gov). Reflectances in band 5 at 1240 $\mathrm{nm}$, band 6 at $1640 \mathrm{~nm}$, and band 7 at $2130 \mathrm{~nm}$ have been used to retrieve water contents relative to reflectance in band 2, centered at $858 \mathrm{~nm}$ (Fensholt and Sandholt, 2003; Gao, 1996; Wang et al., 2008; Xiao et al., 2005; Zarco-Tejada et al., 2003). Fensholt and Sandholt (2003) developed SIWSI using MODIS bands 2,5 , and 6 , showing strong correlation with surface soil moisture measurements in the semi-arid Sahel zone of West Africa, and their work also indicated that the band 6 was slightly better than band 5. However, in the study of Wang et al.,
(2008) for sensitivity analysis of MODIS, SWIR reflectance on the soil/leaf moisture, the band 5 is more sensitive to soil moisture variations than bands 6 and 7. The MODIS bands of 2 and 6 were later also used as land surface water index (LSWI; Xiao et al., 2005) for surface moisture assessment in NDVI and enhanced vegetation index (EVI) tri-index algorithm to monitor temporal regional patterns in paddy rice fields (Xiao et al., 2005).

This paper investigates and tests two kinds of drought indices with relevant bands of satellite data and in-situ ground measurements for the suitability of drought monitoring in the Ningxia Plain of northwestern China. In the study, the importance of drought monitoring and advantages of SWIR bands in sensing soil water are also introduced. The approach, principle, and test-site are described in the Methods section. The availability of the indices is discussed against ground observations of soil moisture in Section 3. Drought indices mapping was also performed on several representative days over the Ningxia Plain. Finally, the practicality of the method and related issues are discussed.

\section{Methods}

\subsection{Study Area}

The study area was located in the Ningxia Plain, which is a typical arid region in northwestern China with an average annual precipitation (AAP) of $160 \sim 650 \mathrm{~mm}$. The field campaigns were conducted in Yongning and Guyuan Counties, located in north and south of Ningxia, respectively (Figure 1). There is an obvious difference in AAP in the two counties: approximately $200 \mathrm{~mm}$ in Yongning and $400 \mathrm{~mm}$ in Guyuan.

The periods of wheat and maize cultivation in the two tested regions were 1 April $\sim 20$ July and 2 May $\sim 8$ September, respectively. A total of six square plots were selected as the test sites, with two plots in Yongning and four in Guyuan. Each of the six plots was about $1 \mathrm{~km}^{2}$ in area. Two of the plots in Yongning were planted with spring wheat and summer maize in a mixed cropping system during May $\sim$ July. While the plots are under wheat only before May, they are under maize only after July 20. Two plots of spring wheat and another two of summer maize were used in Guyuan. Furthermore, the plots were under either wheat or maize before planting and after harvest, and thereafter the fields laid bare. Due to labor constrains, field measurements in Guyuan was ended after July 3.

Field measurements were conducted in sync with the time of satellite overpass under clear sky conditions during the seasons of crop growth in 2009 (Table 1). Although MODIS SWIR data resolution is $500 \mathrm{~m}$ (details in the next paragraph), $1 \mathrm{~km}^{2}$ plots were used to mitigate MODIS data registration errors and field-sampling edge effects. Five diagonal points were sampled in each plot, geo-located using GPS and then averaged for pixel information of MODIS (Figure 1). The study measures gravimetric soil moisture, bulk density, and field capacity at 10 and $20 \mathrm{~cm}$ soil depths. It should be noted that the volumetric soil moisture was adopted to eliminate the effects of soil texture and to avail the description of spatial information on drought. 


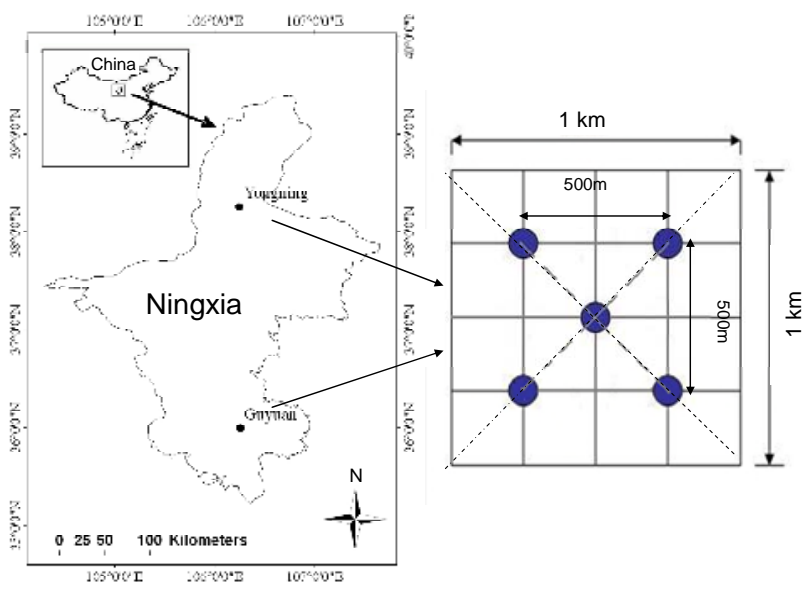

Figure 1. Location map of the study area.

Table 1. Time of Ground Observations under Clear Sky Conditions in the Ningxia Plain Study Area

\begin{tabular}{|c|c|c|c|}
\hline \multirow{2}{*}{ ID } & \multirow{2}{*}{ Date (year-month-day) } & \multicolumn{2}{|c|}{ County } \\
\hline & & Yongning & Guyuan \\
\hline 1 & 2009.04 .03 & & + \\
\hline 2 & 2009.04 .13 & & + \\
\hline 3 & 2009.04 .25 & & + \\
\hline 4 & 2009.05 .04 & & + \\
\hline 5 & 2009.05 .22 & + & \\
\hline 6 & 2009.05 .26 & + & + \\
\hline 7 & 2009.05 .29 & + & \\
\hline 8 & 2009.05 .31 & & + \\
\hline 9 & 2009.06 .08 & + & + \\
\hline 10 & 2009.06 .14 & + & \\
\hline 11 & 2009.06 .17 & + & \\
\hline 12 & 2009.06 .26 & + & + \\
\hline 13 & 2009.06 .30 & + & + \\
\hline 14 & 2009.07 .03 & + & + \\
\hline 15 & 2009.07 .14 & + & \\
\hline 16 & 2009.07 .23 & + & \\
\hline 17 & 2009.08 .05 & + & \\
\hline 18 & 2009.08 .07 & + & \\
\hline 19 & 2009.08 .26 & + & \\
\hline 20 & 2009.09 .02 & + & \\
\hline 21 & 2009.09 .11 & + & \\
\hline
\end{tabular}

\subsection{Remote Sensing Data}

The MODIS data was used in this study that unlike TM data, which are limited in temporal coverage, are free, available in daily-time steps, and have narrow bandwidth ranges, widescan ranges, and moderate spatial resolutions. A total of 21 temporal images - daily surface reflectance (TERRA/MODIS MOD09GA) —of MODIS products corresponding to ground observations are ordered from NASA at http://edcimswww.cr. usgs.gov/pub/imswelcome/. The MYD09 data product is a 7band product with $500 \mathrm{~m}$ resolution that provides estimates of surface spectral reflectance in each band.

The bands were corrected for the effects of atmospheric gases, aerosols, and cirrus clouds (Vermote and Vermeulen,
1999). MYD09GA includes quality control descriptions and has been widely tested/validated (in time and space) with groundtruth data. The data were downloaded in SIN (sine) projection with HDF format and then re-projected to Albers equal area projection in GeoTIFF format using MRT (MODIS Re-projection Tool) platform. All the images were acquired for days with clear skies.

\subsection{Shortwave Infrared Water Indices}

This study used an approach involving information from the NIR shortwave lengths and two configurations of tested SWIR water stress indices. Regarding MODIS, SWIR bands were the $5(1230 \sim 1250 \mathrm{~nm}), 6(1628 \sim 1652 \mathrm{~nm})$, and 7 (2105 $\sim 2155 \mathrm{~nm}$ ) bands. However, there was severe stripe noise in band 5 of the images for China because of complex environmental and instrumental factors, affecting calculations and applications of several of the MODIS SWIR parameters. Although some correction methods exist (Rakwatin et al., 2007; Wang et al., 2008; Wang et al., 2011), MODIS band 5 was not used due to the limited correction accuracy and index convenience. Hence, only MODIS bands 6 and 7 were eventually used in this work.

The index SIWSI is computed as follows:

$$
\operatorname{SIWSI}(i, 2)=\frac{\rho_{i}-\rho_{2}}{\rho_{i}+\rho_{2}}
$$

where $\rho_{i}$ is MODIS channel 6 or 7 reflectance and $\rho_{2}$ is MODIS channel 2 reflectance. The SISWI is a normalized index whose value theoretically varies between -1 and 1 . SISWI index above zero indicates that reflectance in band 6 or 7 is higher than that in band 2, which in turn indicates canopy/soil water stress. In addition, SISWI index below zero indicates a consequence of higher reflectance in channel 2 than in channel 6 or 7, which in turn indicates the existence of sufficient soil pore water. $\mathrm{SIWSI}_{6,2}$ and $\mathrm{SIWSI}_{7,2}$ were eventually constructed from the index series.

The other index SPSI was first developed by Ghulam et al. (2007a) to estimate vegetation water content from TM data. The index also adopts NIR and SWIR bands, wherein the former serves as a reference channel and the latter as a measured channel. This reference-measured channel configuration has been confirmed to be sensitive to water absorption (Cheng et al., 2008; Ghulam et al., 2007b; Fensholt and Sandholt, 2003). Ghulam et al. (2007a) also showed that this index has a good potential for estimating vegetation water content. As vegetation water is mainly supplied by stored soil water, the index could be closely related to the soil water content. SPSI index can be expressed as follows:

$$
S P S I=\frac{1}{\sqrt{M^{2}+1}}\left(R_{S W I R}+R_{N I R}\right)
$$

where $M$ is the baseline slope of NIR-SWIR and $R_{\text {SWIR }}$ and $R_{N I R}$ are the atmospherically corrected reflectances of NIR and 
SWIR bands, respectively. See Figure 2 for the plotted series of SPSI.

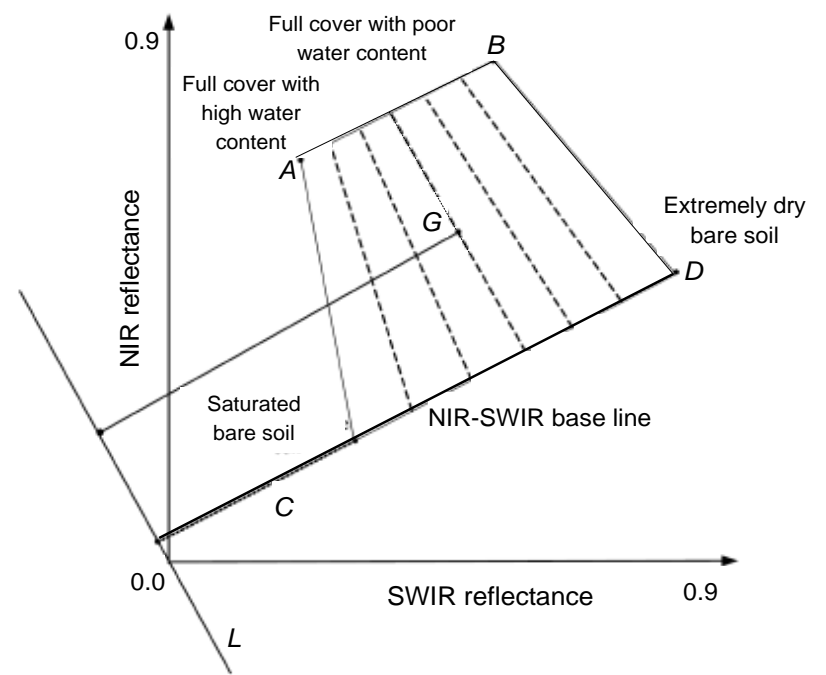

Figure 2. Sketch map of SPSI, here dashed lines refer to FMC isolines (Cited from Ghulam et al 2007a).

In NIR-SWIR space, the distance from a random point $\mathrm{G}$ to $L$ represents vegetation water stress for a vegetated surface. It implies that more the distance between NIR and SWIR, the stronger the water stress and the soil water stress. More importantly, this eventually implies that information on drought or soil water content can be detected and mapped using SPSI index. Thus, SWIR bands 6 and 7 were used to derive SPSI $_{6,2}$ and $\mathrm{SPSI}_{7,2}$, respectively.

\section{Results and Discusssions}

\subsection{Relationship among SIWSI, SPSI, and Soil Moisture}

Several SWIR drought indices derived from satellite $\mathrm{SIWSI}_{6,2}, \mathrm{SIWSI}_{7,2}, \mathrm{SPSI}_{6,2}$, and $\mathrm{SPSI}_{7,2}$ were tested against ground-based measurements of soil moisture (Figure 3 and Figure 4). Volumetric soil water contents in the 10 and $20 \mathrm{~cm}$ soil layers reflect water availability for plant photosynthesis. In addition, the decreasing soil moisture leads to an increase in the satellite-derived indices.

SIWSI $_{6,2}$ and SIWSI $_{7,2}$ were plotted against soil moisture (Figure 3) for the period between April 3 and September 11. A linear relation was determined between SIWSI $_{6,2}$ and $r^{2}=$ 0.75 and 0.74 at the $0 \sim 10$ and $0 \sim 20 \mathrm{~cm}$ soil depths, respectively. The scatter around the regression line appeared to be higher for low values of SIWSI $_{6,2}$, indicating no water stress conditions. The relation between SIWSI $_{7,2}$ and soil moisture was also high $\left(r^{2}=0.73\right)$ (Figure 3). The results indicated that the $\mathrm{SIWSI}_{6,2}$ performs slightly better than $\mathrm{SIWSI}_{7,2}$. The scatter around the regression line was of similar magnitude as that in $\operatorname{SIWSI}_{6,2}$, but the range of dynamics in $\mathrm{SIWSI}_{7,2}$ was larger than in SIWSI $_{6,2}$. This demonstrates that SIWSI could well reflect variations in the soil water content, revealing its potential for applications in evaluating the state of dryness of a given region.

In relation to other methods such as the Ts/NDVI space approach (Fensholt and Sandholt, 2003), SIWSI is a valuable supplement when used to derive information on canopy water stress. This is because SIWSI could be used in very sparse vegetation regions (MODIS NDVI $<0.4$ ). It is therefore reasonable to state that SIWSI is suitable for under-vegetated conditions in terms of band configuration. Furthermore, SIWSI is better than Ts/NDVI space approach in assimilating MODIS data because SIWSI uses SWIR bands with spatial resolution of 500 $\mathrm{m}$, whereas Ts/NDVI uses thermal bands with a resolution of $1 \mathrm{~km}$.

Similarly, $\mathrm{SPSI}_{6,2}$ and $\mathrm{SPSI}_{7,2}$ were plotted against soil moisture in Figure 4 for the period between April 3 and September 11. However, in comparison with SIWSI, the best-fit relationship between SPSI indices and soil moisture was logarithmic. This is similar to the relation between SPSI and canopy water content reported by Ghulam et al. (2007a). The logarithmic relation for $\operatorname{SPSI}_{6,2}$ has $\mathrm{r}^{2}=0.70$ and 0.69 for 10 and $20 \mathrm{~cm}$ soil depths, respectively. The scatter around the regression line also appears to be higher for low values of $\mathrm{SPSI}_{6,2}$, indicating no water stress conditions. The relation between SPSI $_{7,2}$ and soil moisture (Figure 4) is also high with $\mathrm{r}^{2}=0.76$ and 0.75 for 10 and $20 \mathrm{~cm}$ soil depths, respectively. In these plots, $\mathrm{SPSI}_{6,2}$ performs marginally weaker than $\mathrm{SPSI}_{6,2}$. SPSI has also been shown to be a good indicator for soil water content under vegetation conditions (Ghulam et al., 2007a).

Although good relationships were noted among the indices and soil moisture, a bi-data cluster is obvious in the plots in Figure 3 and Figure 4. There are high-value and low-value clusters of soil moisture, induced by the geographical differences between Yongning and Guyuan Counties. The medium value is relatively scarce, accounting for about $10 \sim 20 \%$ of the values. Because of the cluster nature of the plots, more data is needed for further studies to cover the whole range of soil water content.

In addition, although some studies (Fensholt and Sandholt, 2003; Wang et al., 2008) show which band is superior in MODIS SWIR bands 5, 6, and 7, e.g., the MODIS band 6 is slighter better than band 5 as per Fensholt and Sandholt (2003) and the MODIS band 5 is most sensitive to soil moisture among the three bands as per Wang et al. (2008). But the MODIS band 6 has no obvious evidence of superiority than band 7 for the potential of estimating canopy/soil water content in this study (band 5 has not been discussed for its speckle, more work is required).

As outlined in the Introduction section of this paper, several studies (Gao et al., 2008, 2011; Ghulam et al., 2008; Fensholt and Sandholt, 2003; Patel et al., 2009; Qin et al., 2008; Wang et al., 2004) have been conducted in relation to the applications or comparisons of these methods including VSWI, TVX, TVDI, SPSI, and SIWSI. Hence, in this study, the methods have not been compared again. The two selected indices were tested against in-situ soil moisture and mapped for dryness in the Ningxia Plain study area. 

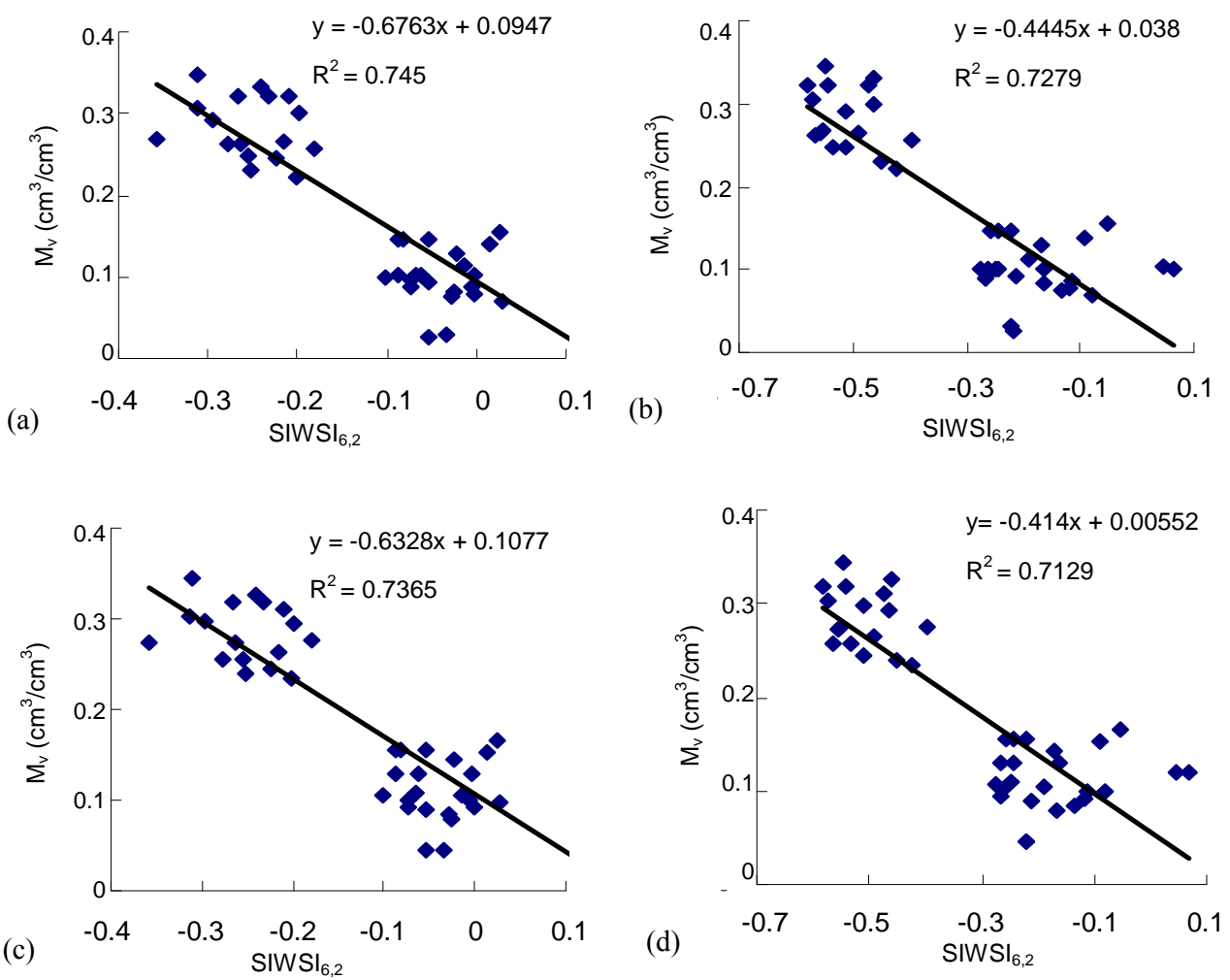

Figure 3. Relations between SIWSI and volumetric soil water at 10-cm (a and b) and 20-cm (c and d) depths.
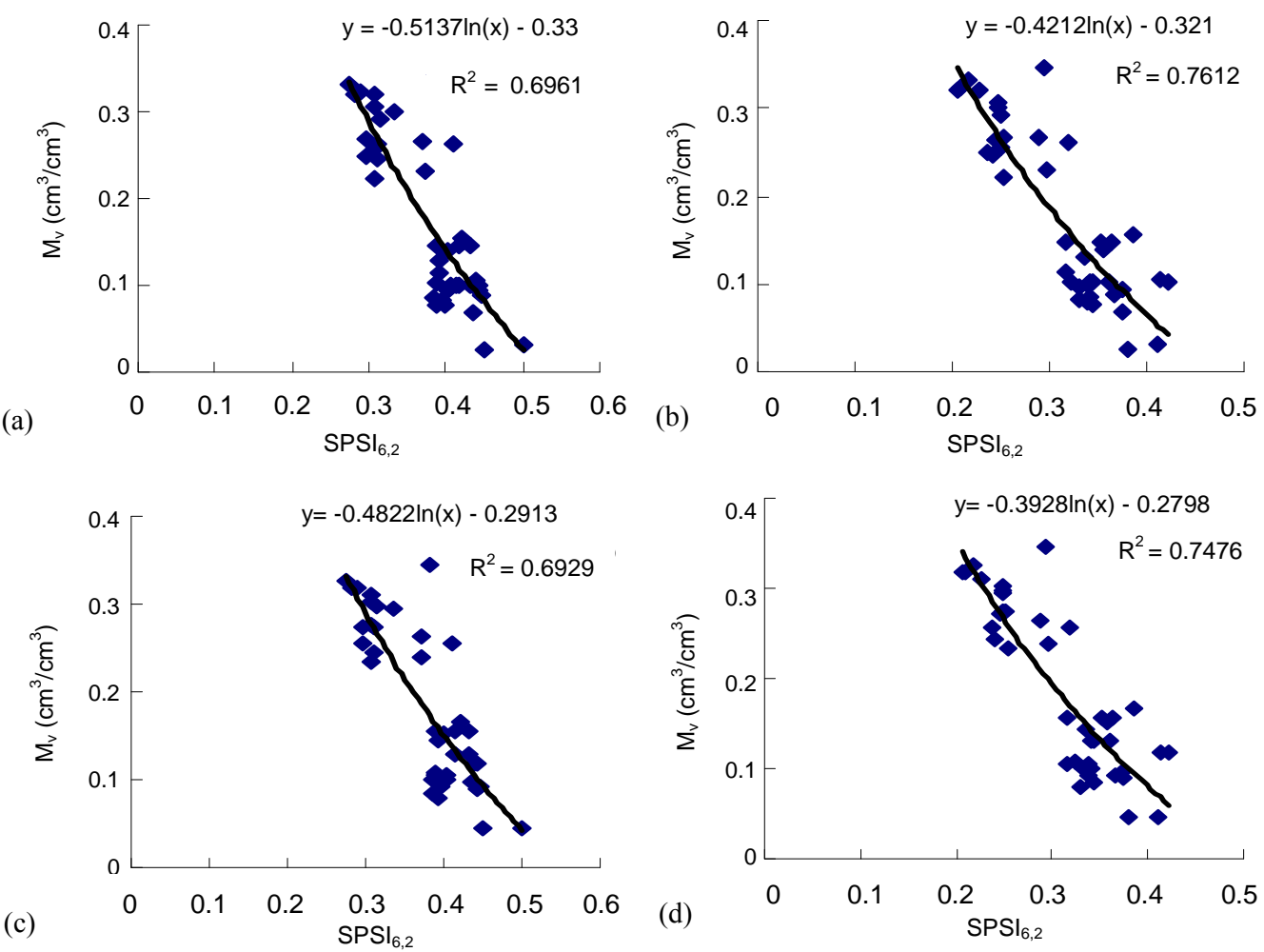

Figure 4. Relations between SPSI and volumetric soil water at 10-cm (a and b) and 20-cm (c and d) soil depths. 

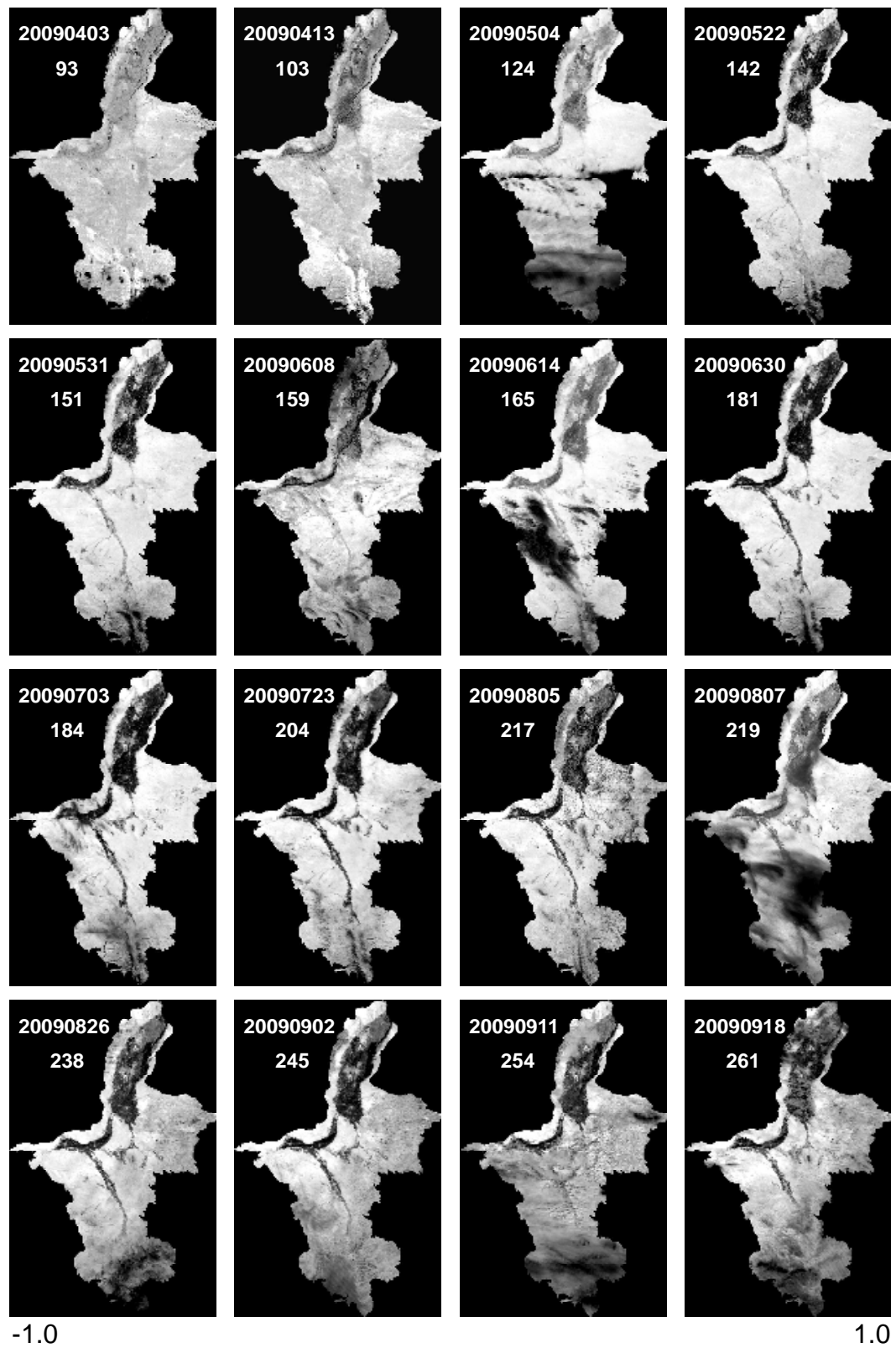

Figure 5. Map plots of $\operatorname{SIWSI}_{6,2}$ for the Ningxia Plain study area in northwestern China.

\subsection{Drought Index Mapping}

From the analysis in Section 3.1, the SPSI and SIWSI indices had good ability for detecting drought signals. The indices were therefore used to determine map out dryness in the Ningxia Plain for days with clear sky conditions (Figures 5 8). From Figures $5 \sim 8$, it is obvious that the SPSI and SIWSI indices have similar abilities to detect dryness. Furthermore, it is clear that the central region of the Ningxia Plain is drier than both the northern and southern regions. This could be due the fact that the northern Ningxia Plain has rich irrigation conditions due to its proximity to the Yellow River. In addition, the southern Ningxia Plain has a relatively high rainfall, inducing high soil moisture in this region. The overall indication is that the results of monitoring drought by the SPSI and SIWSI remote sensing-derived indices are consistent with those obtained from field investigations in the Ningxia Plain, suggesting that the indices reliably detect signals of spatial dryness. As drought complexity is a phenomenon usually determined by such conditions as soil moisture, soil/plant water demand, and plant evapotranspiration, it was not analyzed in this study. We plan to focus on issues such as threshold establishment of droughts in future. 

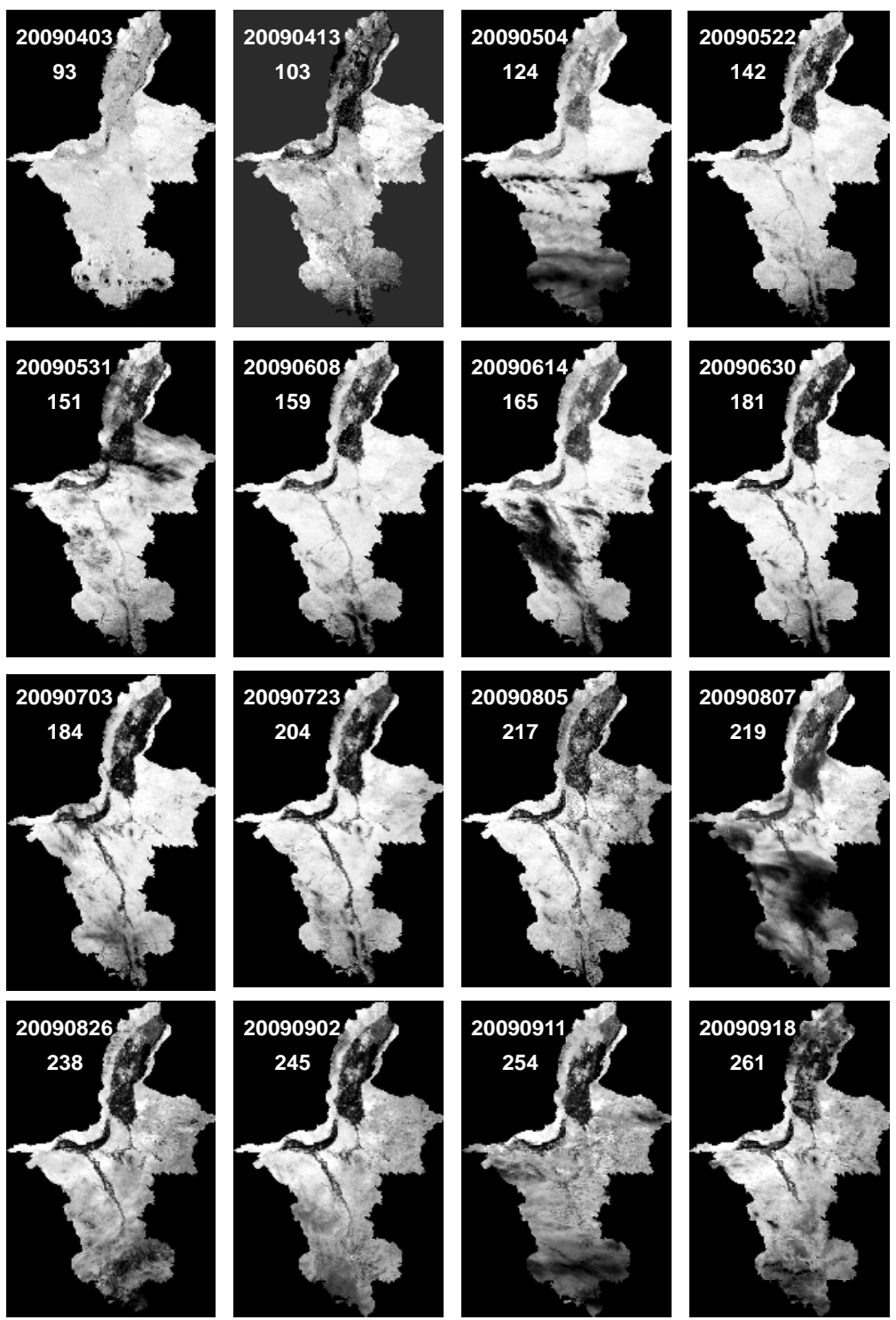

$-1.0$

1.0

Figure 6. Map plots of $\mathrm{SIWSI}_{7,2}$ for the Ningxia Plain study area in northwestern China.

\section{Conclusions}

In this study, two indices (SIWSI and SPSI) constructed from MODIS NIR and SWIR bands were tested against groundbased measurements of soil water content and used to describe the state of dryness in the Ningxia Plain of northwestern China. The SIWSI-SPSI configurations, denoted as SIWSI $_{6,2}$, SIWSI $_{7,2}$, $\mathrm{SPSI}_{6,2}$, and $\mathrm{SPSI}_{7,2}$ were then compared with the measured soil moisture in the 10 and $20 \mathrm{~cm}$ soil layers. The analysis of the two indices shows strong correlation with soil moisture, with slightly higher correlation in the $10 \mathrm{~cm}$ soil layer than that in the $20 \mathrm{~cm}$ soil layer. Although SIWSI 6,2 performs marginally better than SIWSI $_{7,2}$, SPSI $_{6,2}$ performs slightly weaker than $\mathrm{SPSI}_{7,2}$. Given the due limited study and close performances of the shortwave bands 6 and 7, it is difficult to conclude which is better.

The 2009 fieldwork in this study is not completely perfect due to limited data on soil moisture in the middle $10 \sim 20 \%$ of the study area. The SIWSI and SPSI indices should therefore be tested against time series or more inclusive in-situ measurement data (such as ground-based data in the central region of the Ningxia Plain). Irrespectively, however, the analysis shows that the method used in this study sufficiently supplements other determination methods of soil moisture.

It is also important to note that the use of the indices analyzed in this study is not limited to MODIS data or the selected bands. It could also be extended to other SWIR bands and remote sensing data, including hyper-spectral data. From SIWSI 

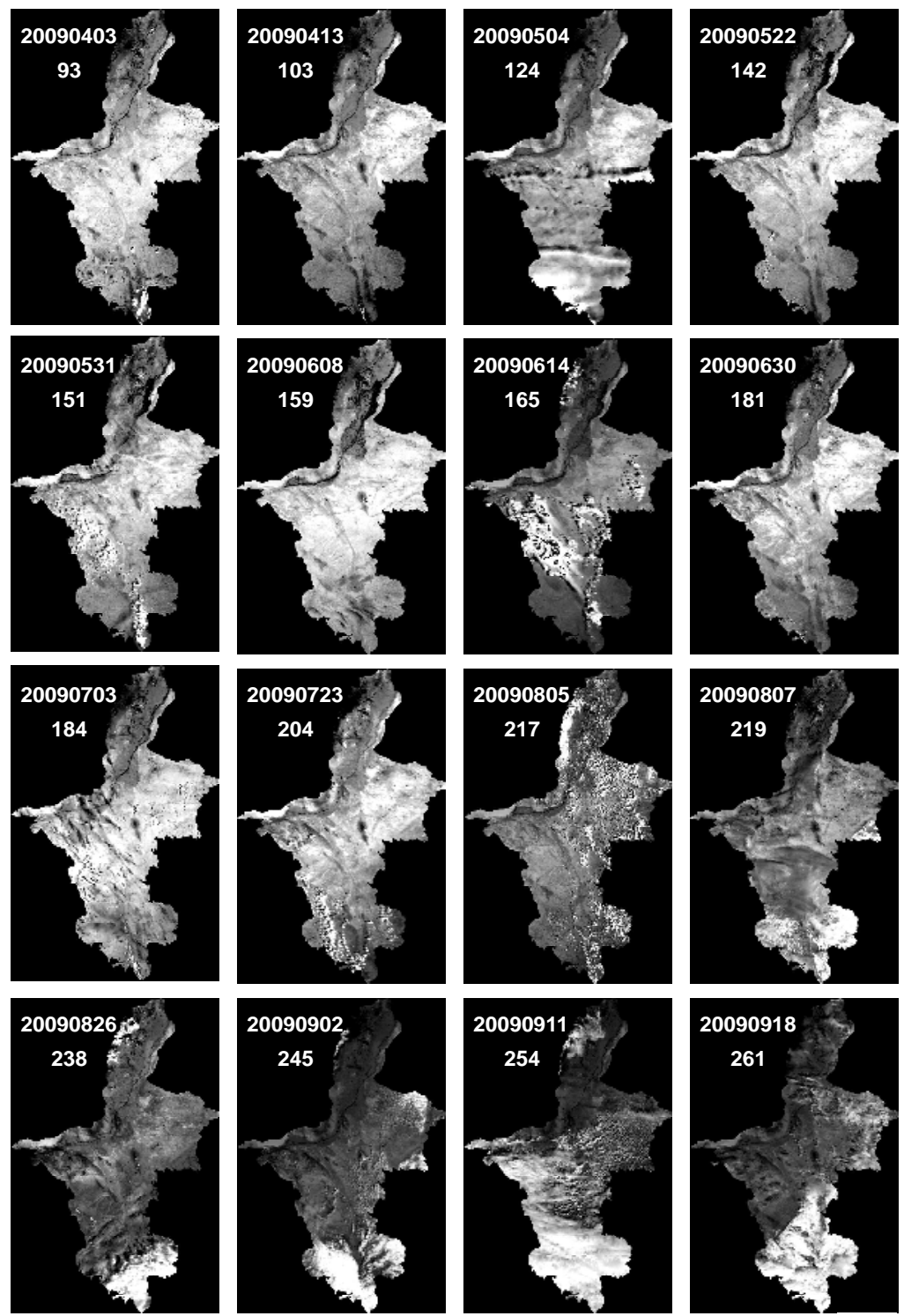

0

Figure 7. Map plots of SPSI $_{6,2}$ for the Ningxia Plain study area in northwestern China.

and SPSI dryness indices, the state of drought in the Ningxia Plain for representative clear sky days was successfully mapped.

Acknowledgments. The authors appreciate the financial support of the National Natural Science Foundation of China (41101313, 41201331), R\&D Special Fund for Public Welfare Industry of China (Meteorology) (GYHY200806022), and the High-Tech Research and Development Program of China (2009AA12Z128 and 2008AA121806-04). We also thank the insightful comments of Dr. Moiwo Juana Paul and the editors and anonymous reviewers.

\section{References}

Carlson, T.N., Perry, E.M., and Schmugge, T.J. (1990). Remote sensing estimation of soil moisture availability and fractional vegetation cover for agricultural fields. Agric. For. Meteorol., 52 (1- 2), 45-69. http://dx.doi.org/10.1016/0168-1923(90)90100-K

Carlson, T.N., Gillies, R.R., and Perry, E.M. (1994).A method to make use of thermal infrared temperature and NDVI measurement to infer surface soil water content and fractional vegetation cover. Remote Sens. Environ., 9(1-2), 161-173. http://dx.doi.org/10.1080 /02757259409532220

Cheng, Y.B., Ustin, S.L., Ria-o, D., and Vanderbilt, V.C. (2008). Water content estimation from hyper spectral images and MODIS indices in Southeastern Arizona. Remote Sens. Environ., 112(2), 363-374. http://dx.doi.org/10.1016/j.rse.2007.01.023 

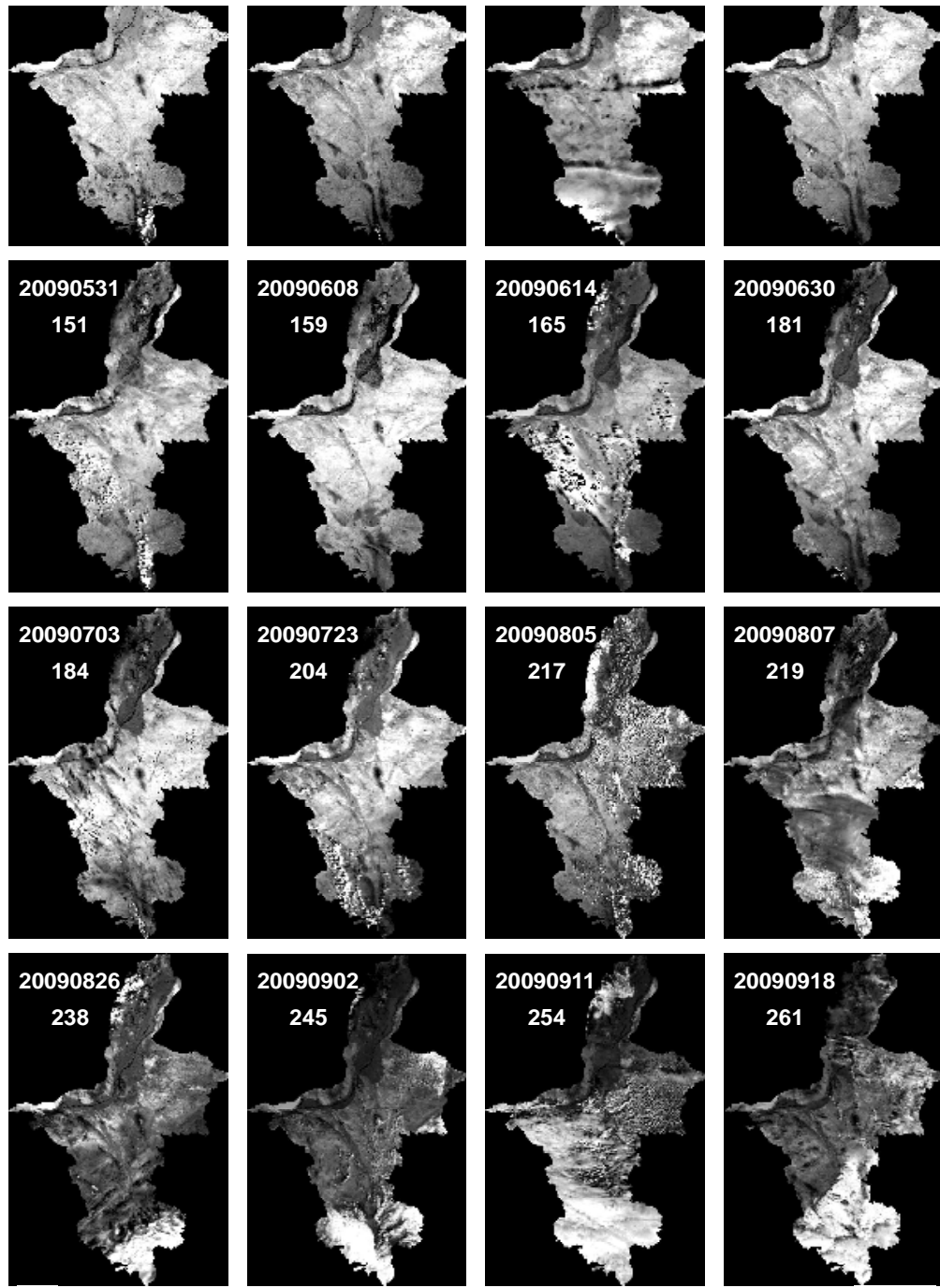

0
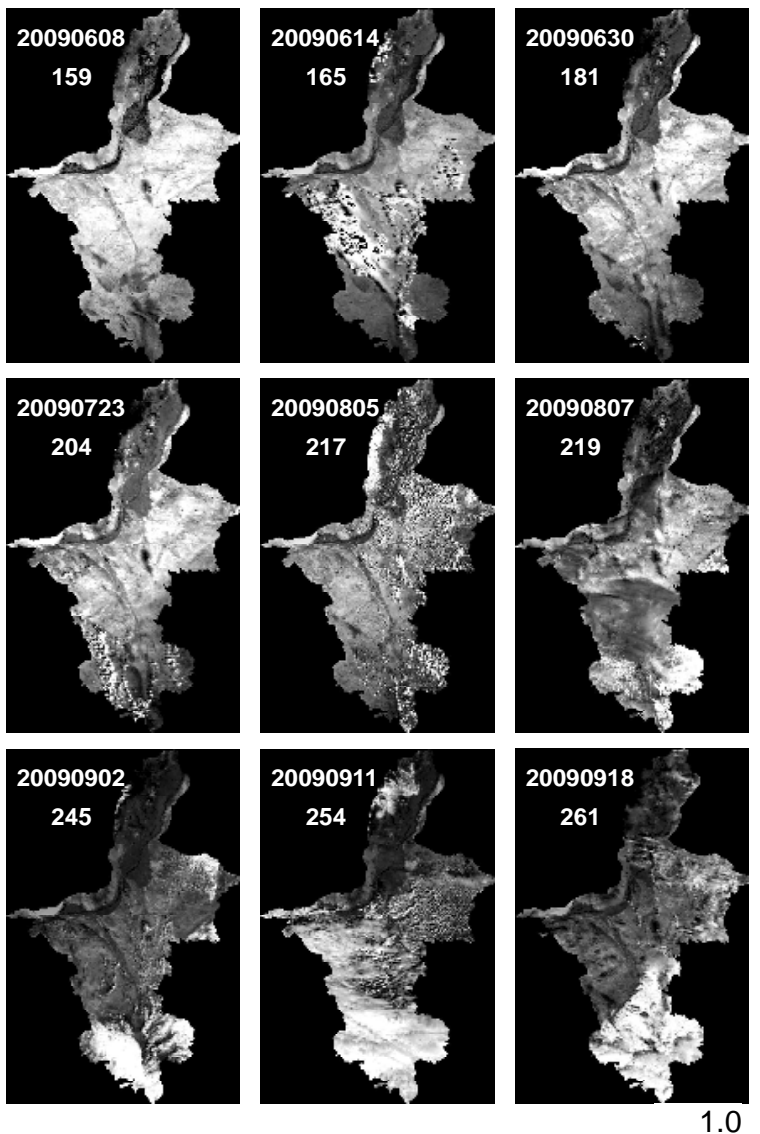

Figure 8. Map plots of $\mathrm{SPSI}_{7,2}$ for the Ningxia Plain study area in northwestern China.

Fensholt, R., and Sandholt, I. (2003). Derivation of a shortwave infrared water stress index from MODIS near- and shortwave infrared data in a semiarid environment. Remote Sens. Environ., 87(1), 111-121. http://dx.doi.org/10.1016/j.rse.2003.07.002

Gao, B.C. (1996). NDWI - A normalized difference index for remote sensing of vegetation liquid water from space. Remote Sens. Environ., 58(3), 257-266. http://dx.doi.org/10.1016/0034-4257(95)000 39-4

Gao, M.F., Qin, Z.H., Zhang, H.O., Lu, L.P., Zhou, X., and Yang, X.C. (2008). Remote sensing of Agro-droughts in Guangdong province of China using MODIS satellite data. Sensors, 8(8), 46874608. http://dx.doi.org/10.3390/s8084687

Gao, Z.Q., Gao, W., and Chang, N.B. (2011). Integrating temperature vegetation dryness index (TVDI) and regional water stress index (RWSI) for drought assessment with the aid of LANDSAT TM/ ETM+ images. Int. J. Appl. Earth Obs. Geoinf., 13(3), 495-503. http://dx.doi.org/10.1016/j.jag.2010.10.005

Ghulam, A., Li, Z., Qin, Q., Tong, Q., Wang, J., Kasimu, A., and Zhu, L. (2007a). A method for canopy water content estimation for highly vegetated surfaces-shortwave infrared perpendicular water stress index. Sci. China Ser. D (Earth Sci.), 50(9), 1359-1368. http://dx.doi.org/10.1007/s11430-007-0086-9

Ghulam, A., Li, Z., Qin, Q., Yimit, H., and Wang, J. (2008). Estimating crop water stress with ETM+ NIR and SWIR data. Agric. For. Meteorol., 148(11), 1679-1695. http://dx.doi.org/10.1016/j.agr formet.2008.05.020

Ghulam, A., Qin, Q., and Zhan, Z. (2007b). Designing of the perpendicular drought index. Environ. Geol., 52(6), 1045-1052. http://dx. doi.org/10.1007/s00254-006-0544-2

Kogan, F.N. (1990). Remote sensing of weather impacts on vegetation in non-homogeneous areas. Int. J. Remote Sens., 11(8), 1405 -1419. http://dx.doi.org/10.1080/01431169008955102

Kogan, F.N. (1995). Application of vegetation index and brightness temperature for drought detection. Adv. Space Res., 15(11), 91-100. http://dx.doi.org/10.1016/0273-1177(95)00079-T

Lambin, E.F., and Ehrlich, D. (1995). Combining vegetation indices and surface temperature for land-cover mapping at broad spatial scales. Int. J. Remote Sens., 16(3), 573-579. http://dx.doi.org/10. 1080/01431169508954423

Lambin, E.F., and Ehrlich, D. (1996). The surface temperature- vege- 
tation index for land cover and land cover change analysis. Int. J. Remote Sens., 17(3), 463-487. http://dx.doi.org/10.1080/01431169 608949021

Nemani R, Pierce L, Running S, and Goward, S,N. (1993). Developing satellite-derived estimates of surface moisture status. $J$. Appl. Meteorol., 32(3), 548-557. http://dx.doi.org/10.1175/15200450(1993)032<0548:DSDEOS > 2.0.CO;2

Patel, N.R., Anapashshab, R., Kumara, S., Sahaa S.K., and Dadhwala V.K. (2009). Assessing potential of MODIS derived temperature/vegetation condition index (TVDI) to infer soil moisture status. Int. J. Remote Sens., 30(1), 23-29. http://dx.doi.org/10.1080/ 01431160802108497

Qin, Q., Ghulam, A., Zhu, L., Wang, L., Li, J., and Nan, P. (2008). Evaluation of MODIS derived perpendicular drought index for estimation of surface dryness over northwestern China. Int. J. Remote Sens., 29(7), 1983-1995. http://dx.doi.org/10.1080/01431160 701355264

Rakwatin, P., Takeuchi, W., and Yasuoka, Y. (2007). Stripe noise reduction in MODIS Data by combining histogram matching with facet filter. IEEE Trans. Geosci. Remote Sens., 45(6), 1844-1856. http://dx.doi.org/10.1109/TGRS.2007.895841

Sandholt, I., Rasmussen, K., and Andersen, J. (2002). A simple interpretation of the surface temperature/vegetation index space for assessment of surface moisture status. Remote Sens. Environ., 79 (2-3), 213-224. http://dx.doi.org/10.1016/S0034-4257(01)00274-7

Tadesse, T., Brownb, J.F., and Hayes, M.J. (2005). A new approach for predicting drought-related vegetation stress: Integrating satellite, climate, and biophysical data over the U.S. central plains. ISPRS J. Photogramm. Remote Sens., 59(4), 244-253. http://dx.doi. org/10.1016/j.isprsjprs.2005.02.003
Thiruvengadachari, S., and Gopalkrishna, H.R. (1993). An integrated PC environment for assessment of drought. Int. J. Remote Sens., 14(17), 3201-3208. http://dx.doi.org/10.1080/01431169308904434 Vermote, E.F., and Vermeulen, A. (1999). Algorithm Technical Background Document, Atmospheric Correction Algorithm: Spectral reflectances (MOD09), Version 4.0, NASA contract NAS5- 96062.

Wang, C.Y., Qi, S.H., Niu, Z., and Wang, J.B. (2004). Evaluating soil moisture status in China using the temperature-vegetation dryness index (TVDI). Can. J. Remote Sens., 2004, 30(5), 671-679. http:// dx.doi.org/10.5589/m04-029

Wang, L.L., Qu, J.J., Hao, X.J., and Zhu, Q.P. (2008). Sensitivity studies of the moisture effects on MODIS SWIR reflectance and vegetation water indices. Int. J. Remote Sens., 29(24), 7065-7075. http://dx.doi.org/10.1080/01431160802226034

Wang, R.B., Zeng, C., Li, P.X., and Shen, H.F. (2011). Terra MODIS band 5 Stripe noise detection and correction using MAP-based algorithm. International Conference on Remote Sensing, Environment and Transportation Engineering, Nanjing, China, June, 2011, $8612-8615$.

Wang, Z.F., Chen, L.F., Gu, X.F., and Yu, T. (2008). Destriping MODIS data based on surface spectral correlation. IEEE Int. Geosci. Remote Sens. Symp., July 2008. IGARSS 2008. 3, 266-269.

Xiao, X., Boles, S., Liu, J., Zhuang, D., Frolking, S., Li, C., Salas, W., and Moore, B. (2005). Mapping paddy rice agriculture in southern China using multi-temporal MODIS images. Remote Sens. Environ., 95(4), 480-492. http://dx.doi.org/10.1016/j.rse.2004.12.009

Zarco-Tejada, P.J., Rueda, C.A., and Ustin, S.L. (2003). Water content estimation in vegetation with MODIS reflectance data and model inversion models. Remote Sens. Environ., 85(1), 109-124. http://dx.doi.org/10.1016/S0034-4257(02)00197-9 